\title{
A reappraisal of generic bisphosphonates in osteoporosis
}

\author{
J. A. Kanis • J.-Y. Reginster • J.-M. Kaufman • \\ J.-D. Ringe • J. D. Adachi • M. Hiligsmann • R. Rizzoli • \\ C. Cooper
}

Received: 16 May 2011 / Accepted: 17 June 2011 /Published online: 28 September 2011

(C) International Osteoporosis Foundation and National Osteoporosis Foundation 2011

\begin{abstract}
Summary The competitive price of generic bisphosphonates has had a marked effect on practice guidelines, but an increasing body of evidence suggests that they have more limited effectiveness than generally assumed.

Introduction The purpose of this study is to review the impact of generic bisphosphonates on effectiveness in the treatment of osteoporosis.

Methods This study is a literature review.

Results A substantial body of evidence indicates that many generic formulations of alendronate are more poorly tolerated than the proprietary preparations which results in significantly poorer adherence and thus effectiveness. Poorer effectiveness may result from faster disintegration
\end{abstract}

times of many generics that increase the likelihood of adherence of particulate matter to the oesophageal mucosa. Unfortunately, market authorisation, based on the bioequivalence of generics with a proprietary formulation, does not take into account the potential concerns about safety. The poor adherence of many generic products has implications for guideline development, cost-effectiveness and impact of treatment on the burden of disease.

Conclusions The impact of generic bisphosphonates requires formal testing to re-evaluate their role in the management of osteoporosis.

Keywords Adherence - Cost-effectiveness - Effectiveness · Gastrointestinal side effects

J.-D. Ringe

Medizin. Klinik 4 (Department Rheumatology/Osteology) and

Western German Osteoporosis Center (WOC) at Klinikum

Leverkusen, University of Cologne,

Cologne, Germany

J. D. Adachi

St Joseph's Healthcare and McMaster University,

Hamilton, ON, Canada

R. Rizzoli

University Hospitals and Faculty of Medicine of Geneva,

Geneva, Switzerland

C. Cooper

MRC Lifecourse Epidemiology Unit, University of Southampton, Southampton, UK

C. Cooper

NIHR Musculoskeletal Biomedical Research Unit,

University of Oxford,

Oxford, UK 


\section{Introduction}

The clinical consequences of osteoporosis are mainly the increased incidence of fractures and their associated morbidity and premature mortality. In addition to the negative impact on the quality and quantity of life of the individual, osteoporosis is a costly disease for society. The number of fragility fractures and the societal costs associated with the disease are expected to increase in the future, partly due to changes in demography and improved life expectancy and, in some countries, due to an increase in age-specific incidence of fractures. In 1990, the number of osteoporotic fractures in Europe was estimated to be 2.7 million, with a direct cost of $€ 36$ billion, of which $€ 24.3$ billion were accounted for by hip fractures. Costs are expected to rise to $€ 76.8$ billion by the year 2050 [1] because of the increasing number of the elderly in the population.

The importance of developing treatments that reduce the risk of fracture is evident, both from an individual and a societal perspective, and a number of agents are available that have been shown in randomised controlled trials to decrease the risk of vertebral and, in some instances, non-vertebral fracture [2, 3]. Major pharmacological interventions are the bisphosphonates, strontium ranelate, raloxifene, denosumab and parathyroid hormone peptides. Interventions that are approved for the prevention and treatment of osteoporosis in Europe are shown in Table 1. They are approved only for the treatment of postmenopausal osteoporosis, but alendronate, etidronate, risedronate and zoledronic acid are also approved for the prevention and treatment of glucocorticoid-induced osteoporosis [4, 5] and alendronate, risedronate, zoledronate and teriparatide are approved for the treatment of osteoporosis in men $[3,6]$.

Table 1 Spectrum of anti-fracture efficacy of interventions approved in Europe [3]

\begin{tabular}{lccc}
\hline & \multicolumn{3}{l}{ Fracture outcome } \\
\cline { 2 - 4 } Intervention & Vertebral & Non-vertebral & Hip \\
\hline Alendronate & + & + & + \\
Ibandronate & + & $+^{\mathrm{a}}$ & $\mathrm{NCE}$ \\
Denosumab & + & + & + \\
Risedronate & + & + & + \\
Zoledronic acid & + & + & + \\
Raloxifene & + & $\mathrm{NCE}$ & $\mathrm{NCE}$ \\
Strontium ranelate & + & + & $+{ }^{\mathrm{a}}$ \\
Teriparatide & + & + & $\mathrm{NCE}$ \\
PTH (1-84) & + & $\mathrm{NCE}$ & $\mathrm{NCE}$ \\
\end{tabular}

NCE no convincing effects. PTH recombinant human parathyroid hormone

${ }^{\mathrm{a}}$ In subsets of patients (post hoc analysis)
All these interventions have been shown to reduce the risk of vertebral fracture when given with calcium and vitamin D supplements. Some have been shown also to reduce the risk of non-vertebral fractures or specifically hip fractures. Of the available options, alendronate, risedronate, zoledronic acid, denosumab and strontium ranelate reduce vertebral, non-vertebral and hip fractures [7-15] (see Table 1). The reduction in vertebral fracture rate has been between $50 \%$ and $70 \%$ whereas the magnitude of reduction in non-vertebral fracture, where demonstrated, has generally been smaller and in the order of $15-25 \%$. Because of the broader spectrum of anti-fracture efficacy, these agents are generally regarded as preferred options in the prevention of fractures in postmenopausal women. This distinction may be important because once a fracture occurs, the risk of a subsequent fracture at most common sites is increased independently of bone mineral density, and hence, an intervention that covers all major fracture sites is preferable. Notwithstanding, there have been no head-to-head studies with fracture as the primary outcome, so that direct comparison of efficacy between agents is not possible. For this reason, many treatment guidelines did not make a distinction between these agents in terms of any recommendations for their use [16-21].

\section{Impact of generics}

In recent years, the situation has changed markedly because of the advent of generic bisphosphonates with a substantial decrease in price and the impact of this on costeffectiveness. A pan-European study from 2004 estimated the cost-effectiveness of branded alendronate in nine countries [22]. In this study alendronate was shown to be cost saving compared to no treatment in women with osteoporosis (with or without previous vertebral fracture) from the Nordic countries (Norway, Sweden and Denmark). The cost-effectiveness of alendronate compared to no treatment was also within acceptable ranges in Belgium, France, Germany, Italy, Spain and the UK. However, with the rapid decline in the price of the generic alendronate, analyses based on a branded drug price have become obsolete and would require an update. For example, in the above-mentioned study, the annual price of branded alendronate varied between $€ 444$ /year (UK) to $€ 651 /$ year (Denmark). The current drug price for alendronate is less than $€ 300 /$ year in all countries and even as low as $€ 18 /$ year in the UK. Revisiting the analysis using these prices markedly improves the cost-effectiveness of alendronate $[23,24]$ because of the decrease in cost (Fig. 1).

Before the advent of generic bisphosphonates, practice guidelines in the UK did not consider first-line treatment, and recommendations were largely based on the spectrum 


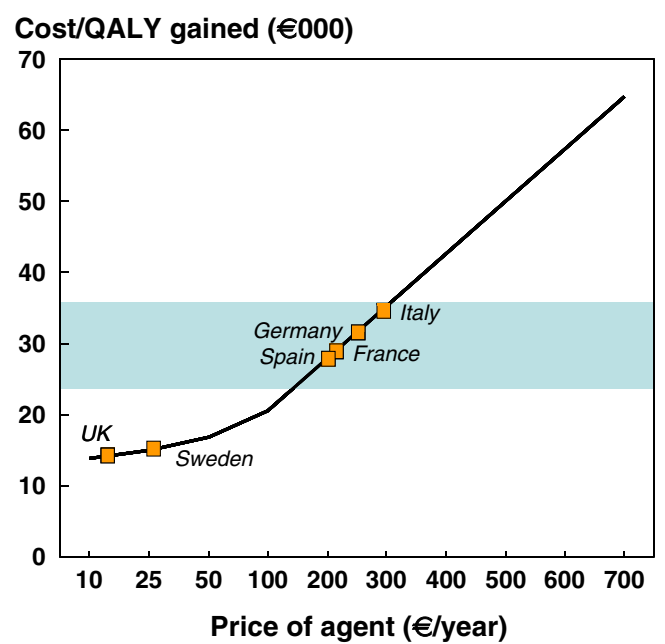

Fig. 1 Impact of price of intervention on cost-effectiveness for a woman from Sweden aged 65 years and a twofold increased risk of fracture is described by the continuous line. The shaded area approximates the willingness to pay by the National Institute for Health and Clinical Excellence (NICE) in the UK. The symbols represent the cost of generic alendronate in several EU counties Assumed RRR $=35 \%$; Costs and effects discounted at 3\%; Includes cost in added life-years; Source, reference model of the International Osteoporosis Foundation [25]. For other assumptions, see [26]

of activity of the agent and side effects [16-21, 27]. As a consequence of the marked effect of the price of intervention on cost-effectiveness and the relatively stable price of other interventions, practice guidelines in the UK and elsewhere recommend that generic alendronate be viewed as first-line treatment $[3,28,29]$, and generic alendronate now dominates many European markets [23]. This view, based on cost minimisation, is sustainable provided that cost is reduced without sacrificing effectiveness. This appears not to be the case and may in part represent a failure of the regulatory pathway.

\section{Regulatory background to generics}

Most health care systems today have to deal with the challenging obligation of limiting and minimising health expenditure. Given the increasing costs of health care, many global initiatives [30] and national health policies worldwide recommend therapeutic substitution. Therapeutic substitution is the interchange of a less costly drug in place of another treatment, based on the premise that the cheaper version has the same therapeutic effect [31]. Usually, a generic version of the same drug is developed and used as a strategy to reduce rapidly prescribing costs $[32,33]$.

The generic forms of a reference drug are usually marketed after the patent of the branded agent has expired, i.e. after 10 years or more. As defined by the Directive 2001/83/EC of the European Community [34], a generic drug contains an active component qualitatively and quantitatively identical to the reference drug, but excipients may differ. The reference is the original and innovative agent that has been made available to the market and registered on the basis of a complete registration procedure, with full quality, safety and efficacy data. In contrast, marketing the generic form necessitates only an abridged procedure since it does not concern a new chemical entity. The manufacturer of a generic drug can submit an application for marketing authorisation built on the basis of the information provided by the full marketing procedure of the reference drug and on proving the bioequivalence of the two drugs, generic and reference, as recommended by the European Medicine Agency guideline [34]. The avoidance of studies of efficacy and safety reduces markedly the development costs permitting price reduction because major development costs are avoided.

Market authorisation of a generic substitute relies heavily on the demonstration of bioequivalence. A bioequivalence study is a randomized clinical study, usually in healthy volunteers, that compares the bioavailability between the test product and a reference product. For oral agents, such as the bisphosphonates, this will include a comparison of absorption (area under the curve, AUC), the rate of absorption (Tmax) and peak concentration (Cmax) based on serum concentration or more usually with the bisphosphonates on cumulative urinary excretion (Ae) (Fig. 2). Equivalence is inferred when, for both AUC and Cmax, the $90 \%$ confidence interval for the ratio of geometric means for test and reference formulations lies within the range of $0.8-1.25$ [34].

\section{Branded vs. generic bisphosphonates}

Gastrointestinal intolerance of amino-bisphosphonates is a well recognised side effect due in part to local effects on the

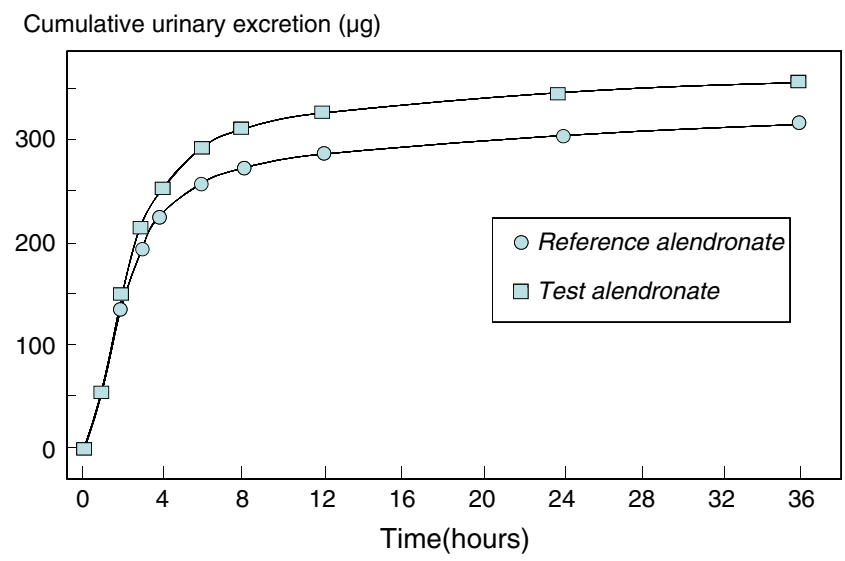

Fig. 2 Mean cumulative urinary excretion of alendronate $70 \mathrm{mg}$ by mouth after the administration of test and reference formulations $(n=$ 70) [redrawn from 61] 
oesophageal or gastric mucosa. Gastrointestinal adverse effects that have been associated with oral bisphosphonates include dysphagia, oesophagitis, stomach ulceration and, more arguably, oesophageal cancer [35-39]. With alendronate, chemical oesophagitis may occur, promoted by an inadequate amount of water when swallowing the pill and failure to remain upright for some time after taking the drug $[36,40]$. These adverse effects are mitigated somewhat by weekly or monthly rather than daily formulations but contribute to the poor adherence associated with the longterm management of patients with osteoporosis [41-46].

Since the introduction of generic bisphosphonates, reports have consistently concluded that adherence is poorer in patients who take generic alendronate than with the original product. In an insurance claims database of upper gastrointestinal tract outcomes in 6,962 patients either on branded or generic alendronate for a minimum of 3 months (10 mg daily), significantly higher discontinuation rates were noted with the generic versions of alendronate as compared to the brand [47]. Incident rate ratios (IRR) for treatment discontinuation were higher with two generic formulations compared to the proprietary product (IRR, 1.3; 95\% CI 1.04-1.63). Adherence (medication possession ratio, $>80 \%$ ) was higher (IRR, $1.19 ; 95 \%$ CI 1.11-1.27) and the new use of gastric medications (3.4$4.9 \%)$ lower with branded than with the generic equivalent (IRR, 0.71; 95\% CI 0.53-0.95). Similar findings were reported from a large Canadian claims database [48] that examined adherence with a weekly dose $(70 \mathrm{mg})$. After adjusting for potential confounding covariates, patients who were started on weekly oral generic alendronate remained at a higher risk of early discontinuation compared to patients initiated with weekly oral branded alendronate (IRR, 2.08; 95\% CI 1.89-2.28) (Fig. 3).

It might be argued that the introduction of generic alendronate resulted in a widening of the prescription market with the inclusion of patients less motivated to therapy and thus less compliant than formerly. This seems unlikely given that the same phenomenon was noted when patients established on treatment were switched from a branded to generic formulation. Following the introduction of generic alendronate to the Canadian market in July 2005 , over $80 \%$ of patients were automatically switched from branded to generic alendronate without notification. An increase in the reports of adverse effects prompted a review of the case notes of 301 women with osteoporosis aged 50 years or more who had been established on treatment with alendronate $10 \mathrm{mg}$ daily or $70 \mathrm{mg}$ weekly between 2003 and 2007 [49]. The rate of adverse events resulting in the discontinuation of treatment was significantly higher after the introduction of generic alendronate than before $(5.3 / 100$ vs. $1.2 / 100$ patient-years of exposure; $p<0.001)$. The majority of adverse events reported were upper gastrointestinal $(61 \%)$. The higher rates of GI intolerance were associated with more frequent discontinuation of treatment
Fig. 3 Kaplan-Meier curves for the risk of early discontinuation during the year following index date (first dispensation of bisphosphonate) [48] with kind permission from Springer Science + Business Media BV

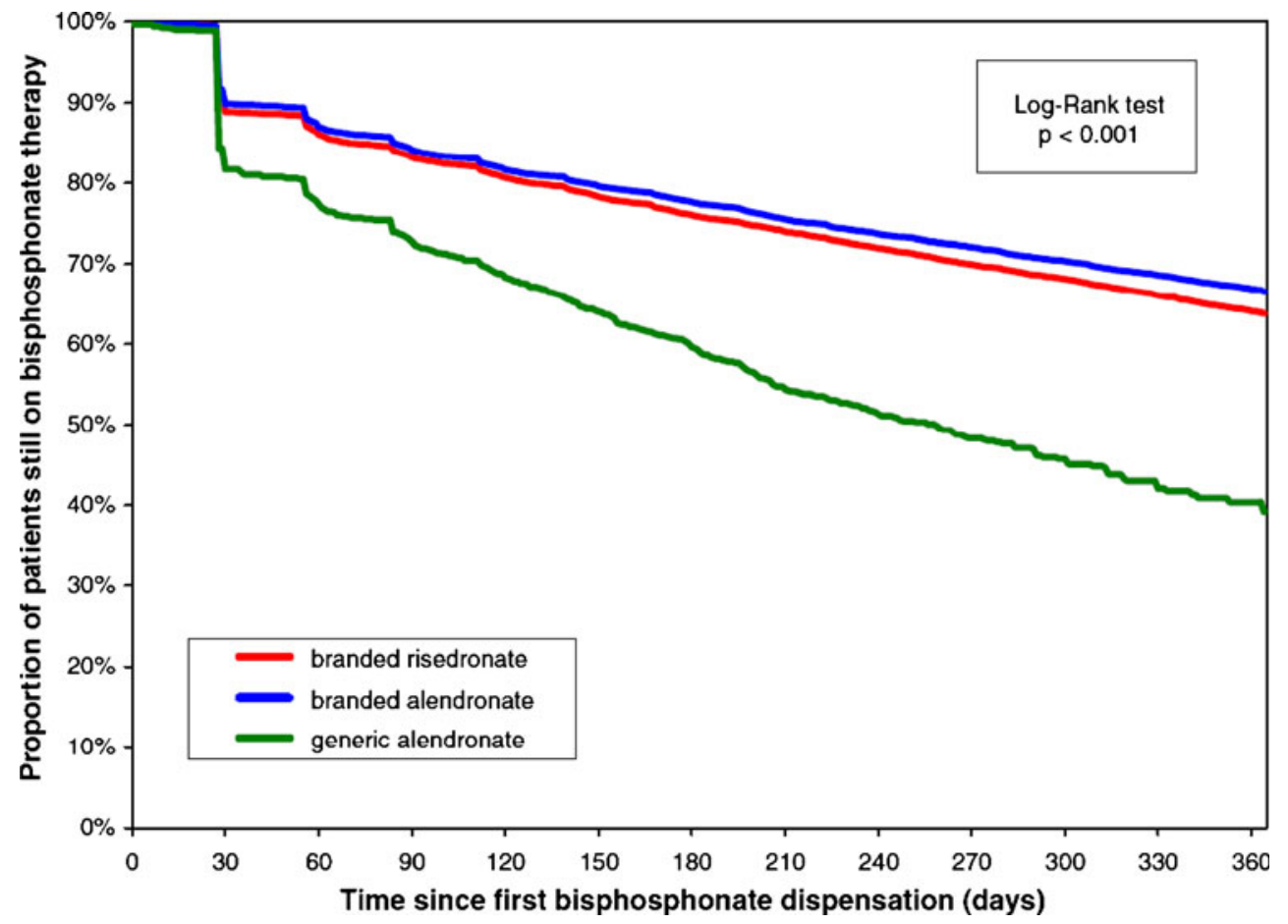


and significant losses of bone mineral density (BMD) at the femoral neck and lumbar spine.

A second retrospective chart review in Germany compared the effects of once weekly branded risedronate or alendronate with generic alendronate on BMD [50]. Of 186 women with postmenopausal osteoporosis, treated for at least 12 months, there was a significantly higher incidence of gastrointestinal (and other) adverse events in women taking the generic drugs. Significantly smaller increments in BMD at the lumbar spine $(p<0.05)$ and total hip $(p<$ 0.01 ) were observed after 1 year in the group receiving generic alendronate compared to those receiving the two branded bisphosphonates.

Thus, the evidence available indicates that many generic formulations are less well tolerated than the proprietary products and that this leads to poorer adherence, in turn associated with a poorer clinical outcome in terms of effectiveness on BMD [51-53] and ultimately in effectiveness on fracture outcomes [44, 51, 54-56].

Because generic drugs in developed markets are shown to be bioequivalent, it might be assumed that the decrease in effectiveness is a result of the poor adherence. There is some evidence that there may be additional effects on drug efficacy. In the case review of Ringe et al. [50] unequal efficacy of the generic vs. branded alendronate and risedronate was observed in the effect on BMD: significantly lower treatment-induced increases in BMD at the lumbar spine $(p<0.05)$ and total hip $(p<0.01)$ were observed after 1 year in the group receiving generic alendronate compared to those receiving the two branded bisphosphonates. In the Canadian survey [49], generic treatment was stopped because of a decrease in BMD in a significant minority of patients. Whether some generic products have lower efficacy remains an open question, and poor adherence provides a plausible reason for the apparent reduction in the effectiveness of the generic products.

\section{Formulation}

The question arises whether poor tolerance is due to differences in the formulation between the generics and their branded equivalents, and there is evidence to suggest that this is indeed the case. Mean disintegration times have been found to be significantly faster for two generic formulations of alendronate available in Canada compared to branded alendronate (with or without vitamin D) or branded risedronate [57]. Disintegration rates of several of the generics available in Europe or the USA were similar to those reported for tablets specifically formulated to disintegrate in the mouth (<30 s) [58-60] (Fig. 4). Many other

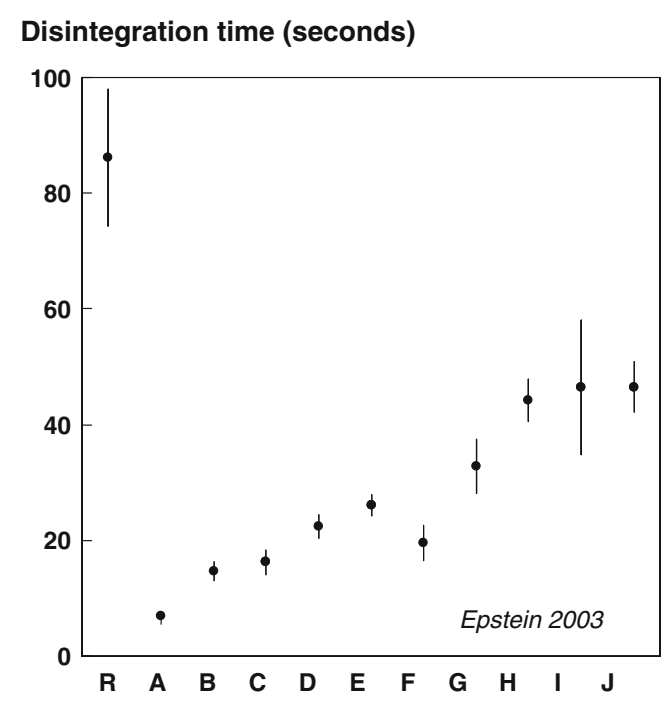

Fig. 4 Disintegration times in vitro of Fosamax 70-mg tablets $(R)$ and ten generic copies from South America [redrawn from 58]

studies have confirmed heterogeneous rates of disintegration [58]. Dissolution rates appear to have much less variability [59-63].

In 2005, Epstein showed a greater irritant response in dogs from a generic alendronate compared to the reference product when tablets of the two formulations were placed at the lower oesophagus: the differences were attributed to the excipients, since the active ingredient (alendronate sodium) and the dose in copy alendronate tablets were similar to branded tablets [64].

Rapid disintegration with semi-particulate alendronate may cause poor tolerance by adhering to the oesophageal mucosa. Such an effect of a majority of generic formulations of alendronate, but not the proprietary products, was shown in vitro on the oesophageal mucosa of pigs [65]. All but one of six generics displayed "cleavage" rupture leaving a large piece of tablet strongly adherent to the oesophageal mucosa.

\section{Discussion}

The evidence reviewed suggests that a high proportion of generic formulations of alendronate and possibly other bisphosphonates are associated with poorer tolerance and more frequent and severe adverse events than the proprietary compound. A plausible mechanism lies in the differences in the formulation of the excipients, rather than in the content of active product. The finding of different disintegration profiles and oesophageal bio-adhesiveness supports this view and suggests that the safety profiles of the different marketed tablets might be not be identical. It 
should be acknowledged that these findings are based on a sample of generic products and that not all generic bisphosphonates should necessarily be tarred with the same brush.

This poses a challenge for regulators in the approval process for generic products with known or suspected upper gastrointestinal toxicity. Marketing authority is usually based on bioequivalence with the presumption of therapeutic equivalence, but this neglects the concerns with safety highlighted in the present review. There is a loophole in the current regulatory requirements for the development of generic agents that exhibit gastrointestinal side effects. We recommend that the approval process for such agents should demand comparative studies of gastrointestinal tolerance and safety in relevant target populations. It is of interest that the Australian agency has recently rejected a generic approval because of uncertainties over safety [66].

Major consequences of poor tolerance are the impact of side effects in patients that continue medication, poor compliance and persistence and the decreased effectiveness of treatment due to poor compliance and persistence. These have implications for management guidelines and health economic assessment.

Even small relatively modest side effects may have implications for cost-effectiveness if their prevalence is high among those that take the agent concerned. An example is shown in Fig. 5 which shows the costeffectiveness of intervention as a function of the cost of

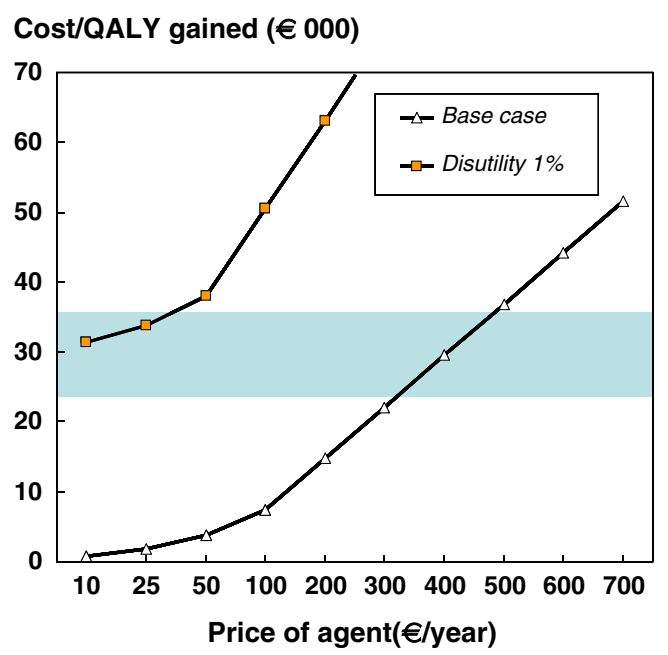

Fig. 5 Cost-effectiveness of an agent according to price for a woman from Sweden aged 65 years and a twofold increased risk of fracture. The shaded area approximates the willingness to pay by NICE in the UK. The lower slope (triangles) assumes no adverse effect of the agent on quality of life, whereas the upper slope (squares) assumes a $1 \%$ decrease in quality of life due to adverse effects of the agent the agent. The lower line (reproduced in Fig. 1) is the scenario where the incidence of long-standing side effects is negligible. The upper curve shows the same clinical scenario, but where long-standing intolerance reduces quality of life on average by $1 \%$ compared to patients not taking the drug. Under these assumptions, treatments costing up to $€ 450 /$ year are within accepted bounds of cost-effectiveness, but a product with significant side effects would be cost-ineffective even with a drug price tenfold lower at $€ 45 /$ year. In the absence of empirical data, the scenarios are hypothetical, but illustrate the need for such data and, in their absence, suggest that health economic evaluations of generic bisphosphonates [22, 24, $28,67]$ should be cautiously interpreted. Thus, despite firm recommendations to introduce generic medication at treatment initiation or to switch from brands to generic forms of treatment [28], further health economic analyses with generic specific data are required to confirm the validity of such recommendation and quantify the real gain of substituting generic formulations in place of branded medications.

The impact of poor adherence (rather than side effects) on cost-effectiveness is a relatively recent field of health economics with the creation of models that capture the elements of adherence [22, 68]. Poor persistence results in lower costs and lower effectiveness so that the effects move in the same direction and may have marginal impact on the ratio of cost with effectiveness. This, however, neglects the acquisition costs to identify the patient (BMD tests, visits to a physician, etc.) so that cost-effectiveness is adversely affected. The problem is compounded by poor compliance when patients may take their bisphosphonate in a nonfasting state or with calcium-containing liquids. Under these circumstances, the cost remains the same (patients take the drug), but the effectiveness is reduced. When comparing full adherence with partial adherence, the variables that on average had the greatest beneficial effect on the incremental cost-effectiveness included the efficacy of the intervention, drug price, underlying risk of fractures, the fraction of benefit assigned to partial adherence, and fracture-related costs. For example, a $1 \%$ increase in drug effect lowered the incremental costeffectiveness ratio (ICER) by $2.2 \%$, and a $1 \%$ increase in the drug price of the high-adherence comparator increased the ICER by $2.7 \%$ [69].

The principal effect of poor adherence is that it leaves large groups of patients untreated, such that the public health objectives of fracture reduction are not met. Interventions that are associated with high adherence have a considerable impact on the number of avoided fracturesa feature that appears questionable in the case of generic bisphosphonates. 
Acknowledgements This review was developed following a meeting on generic bisphosphonates organised by the European Society for Clinical and Economic Aspects of Osteoporosis and Osteoarthritis (ESCEO) in Paris, December 2010, the findings of which were reviewed at an ESCEO-FROMO Symposium of the IOF-ESCEO European Congress on Osteoporosis and Osteoarthritis in Valencia, March 2011. The Alliance for Better Bone Health (sanofi-aventis and Warner Chilcott) provided an unrestricted educational grant to support scientific activities of ESCEO at the European Congress on Osteoporosis in Valencia in March 2011. This publication summarises the discussions of a meeting organised by ESCEO at that congress, with the topic; Generics versus branded medication in osteoporosis: The Alliance has had no editorial control over this publication.

Competing interests JA Kanis receives consulting fees, paid advisory boards, lecture fees and/or grant support from the majority of companies concerned with skeletal metabolism.

J-Y Reginster receives consulting fees, paid advisory boards, lecture fees and/or grant support from Ebewee Pharma, Zodiac, Analis, Theramex, Nycomed, Novo-Nordisk, Bristol Myers Squibb, Merck Sharp \& Dohme, IBSA, Genevrier, Novartis, Servier, Roche, GlaxoSmithKline, Teijin, Teva, Merckle, Negma, NPS, Amgen, UCB, Wyeth, Lilly and Rottapharm.

J-M Kaufman receives consulting fees, paid advisory boards, lecture fees and/or grant support from Amgen, Eli Lilly, GlaxoSmithKline, Merck, Novartis, Procter \& Gamble, Roche, SanofiAventis, Servier and Warner Chilcott.

JD Ringe gives advice to and lectures for different pharmaceutical companies in the field of osteoporosis.

JD Adachi receives consulting fees, paid advisory boards, lecture fees or grant support from the following: Amgen, Astra Zeneca, Eli Lilly, GlaxoSmithKline, Merck, Novartis, Nycomed, Pfizer, Procter \& Gamble, Roche, Sanofi-Aventis, Servier, BMS and Wyeth.

M Hiligsmann receives lecture fees and/or grant support from Amgen, Servier and Novartis.

$\mathrm{R}$ Rizzoli receives consulting fees, paid advisory boards and/or lecture fees from most companies concerned with bone disease.

C Cooper receives consulting fees and paid advisory boards for Alliance for Better Bone Health, GlaxoSmithKline, Roche, Merck Sharp and Dohme, Lilly, Amgen, Wyeth, Novartis, Servier and Nycomed.

\section{References}

1. Kanis JA, Johnell O (2005) Requirements for DXA for the management of osteoporosis in Europe. Osteoporos Int 16:229-238

2. Delmas PD (2002) Treatment of postmenopausal osteoporosis. Lancet 359:2018-2026

3. Compston J, Cooper A, Cooper C et al (2009) Guidelines for the diagnosis and management of osteoporosis in postmenopausal women and men from the age of 50 years in the UK. Maturitas 62:105-108

4. Van Staa TP (2006) The pathogenesis, epidemiology and management of glucocorticoid-induced osteoporosis. Calcif Tissue Int 79:129-137

5. Compston JE (2007) Emerging consensus on prevention and treatment of glucocorticoid-induced osteoporosis. Curr Rheumatol Rep 9:78-84

6. Papaioannou A, Morin S, Cheung A et al (2010) 2010 clinical practice guidelines for the diagnosis and management of osteoporosis in Canada: summary. CMAJ 182:1864-1873

7. McClung MR, Geusens P, Miller PD et al (2001) Effect of risedronate on the risk of hip fracture in elderly women. Hip Intervention Program Study Group. N Engl J Med 344:333-340
8. Cummings SR, San Martin J, McClung MR et al (2009) Denosumab for prevention of fractures in postmenopausal women with osteoporosis. N Engl J Med 361:756-765

9. Delmas PD (2008) Clinical potential of RANKL inhibition for the management of postmenopausal osteoporosis and other metabolic bone diseases. J Clin Densitom 11:325-338

10. Meunier PJ, Roux C, Seeman E et al (2004) The effects of strontium ranelate on the risk of vertebral fracture in women with postmenopausal osteoporosis. N Engl J Med 350:459-468

11. Reginster JY, Seeman E, De Vernejoul MC et al (2005) Strontium ranelate reduces the risk of nonvertebral fractures in postmenopausal women with osteoporosis: Treatment of Peripheral Osteoporosis (TROPOS) Study. J Clin Endocrinol Metab 90:2816-2822

12. Black DM, Cummings SR, Karpf DB et al (1996) Randomised trial of effect of alendronate on risk of fracture in women with existing vertebral fractures. Fracture Intervention Trial Research Group. Lancet 348:1535-1541

13. Black DM, Delmas PD, Eastell R et al (2007) Once-yearly zoledronic acid for treatment of postmenopausal osteoporosis. $\mathrm{N}$ Engl J Med 356:1809-1822

14. Harris ST, Watts NB, Genant HK et al (1999) Effects of risedronate treatment on vertebral and nonvertebral fractures in women with postmenopausal osteoporosis: a randomized controlled trial. Vertebral Efficacy with Risedronate Therapy (VERT) Study Group.PG. JAMA 282:11344-11352

15. Lyles KW, Colon-Emeric CS, Magaziner JS et al (2007) Zoledronic acid and clinical fractures and mortality after hip fracture. N Engl J Med 357:1799-1809

16. Agence Française de Sécurité Sanitaire des Produits de Santé (2006) 19/01/2006 - Traitement médicamenteux de l'ostéoporose postménopausique - recommandations de bonne pratique. http://www. afssaps.fr/content/search?SearchText=osteoporose\&ok=Valider

17. Braun J, Pfeilschifter J (2010) Osteoporosis diagnosis and therapy according to the 2010 guidelines. Z Rheumatol 69:327-339

18. Pfeilschifter J (2006) 2006 DVO-guideline for prevention, diagnosis, and therapy of osteoporosis for women after menopause, for men after age 60 executive summary guidelines. Exp Clin Endocrinol Diabetes 114:611-622

19. Adami S, Bertoldo F, Brandi ML et al (2009) Guidelines for the diagnosis, prevention and treatment of osteoporosis. Reumatismo 61:260-284

20. Royal College of Physicians (1999) Osteoporosis: clinical guidelines for the prevention and treatment. Royal College of Physicians, London

21. Kanis JA, Burlet N, Cooper C, Delmas PD, Reginster J-Y, Borgstrom F, Rizzoli R, On behalf of the European Society for Clinical and Economic Aspects of Osteoporosis and Osteoarthritis (ESCEO) (2008) European guidance for the diagnosis and management of osteoporosis in postmenopausal women. Osteoporos Int 19:399-428

22. Strom O, Borgstrom F, Sen SS, Boonen S, Haentjens P, Johnell O, Kanis JA (2007) Cost-effectiveness of alendronate in the treatment of postmenopausal women in 9 European countries-an economic evaluation based on the fracture intervention trial. Osteoporos Int 18:1047-1061

23. Kanis J, McCloskey E, Jönsson B, Cooper A, Ström O, Borgström F (2010) An evaluation of the NICE guidance for the prevention of osteoporotic fragility fractures in postmenopausal women. Arch Osteoporos 5:19-48

24. Kanis JA, Adams J, Borgstrom F, Cooper C, Jonsson B, Preedy D, Selby P, Compston J (2008) The cost-effectiveness of alendronate in the management of osteoporosis. Bone 42:4-15

25. Zethraeus N, Borgstrom F, Strom O, Kanis JA, Jonsson B (2007) Cost-effectiveness of the treatment and prevention of osteoporo- 
sis-a review of the literature and a reference model. Osteoporos Int 18:9-23

26. Borgstrom F, Johnell O, Kanis JA, Oden A, Sykes D, Jonsson B (2004) Cost effectiveness of raloxifene in the treatment of osteoporosis in Sweden: an economic evaluation based on the MORE study. Pharmacoeconomics 22:1153-1165

27. Royal College of Physicians and Bone and Tooth Society of Great Britain (2000) Update on pharmacological interventions and an algorithm for management. Royal College of Physicians, London

28. National Institute for Health and Clinical Excellence (2010) Final appraisal determination. Alendronate, etidronate, risedronate, raloxifene and strontium ranelate for the primary prevention of osteoporotic fragility fractures in postmenopausal women. London, NICE. November 2010

29. González M, Guañabens GN, Gómez C et al (2008) (Comité de Redacción, en representación del Comité de Expertos de la SEIOMM para la elaboración de las Guías). Practice guidelines for postmenopausal, steroid-induced and male osteoporosis. Spanish Society for Bone and Mineral Research. Rev Clin Esp 208(suppl 1):1-24

30. Figueras J, McKee M, Lessof S et al (2008) Health systems, health and wealth: assessing the case for investing in health systems. World Health Organization 2008 and World Health Organization, on behalf of the European Observatory on Health Systems and Policies. Available at: http://www.euro.who.int. Accessed 7 May 2011

31. Johnston A (2010) Challenges of therapeutic substitution of drugs for economic reasons: focus on CVD prevention. CMRO 26:871878

32. Andersson K, Bergström G, Petzold MG et al (2007) Impact of a generic substitution reform on patients' and society's expenditure for pharmaceuticals. Health Policy 81:376-383

33. Hakonsen HH, Eilertsen M, Borge H, Toverud EL (2009) Generic substitution: additional challenge for adherence in hypertensive patients? CMRO 25:2515-2521

34. EMEA (1998) Guideline on the investigation of bioequivalence. CPMP/EWP/QWP/1401/98 Rev.1. Available at: http://www.emea. europa.eu/htms/human/humanguidelines/efficacy.htm. Accessed 7 May 2011

35. Lufkin EG, Argueta R, Whitaker MD et al (1994) Pamidronate: an unrecognized problem in gastrointestinal tolerability. Osteoporos Int 4:320-322

36. De Groen PC, Lubbe DF, Hirsch LJ et al (1996) Esophagitis associated with the use of alendronate. N Engl J Med 335:10161021

37. Naylor G, Davies MH (1996) Oesophageal stricture associated with alendronic acid. Lancet 348:1030-1031

38. Kane S, Borisov N, Brixner D (2004) Pharmacoeconomic evaluation of gastrointestinal tract events during treatment with risedronate or alendronate: a retrospective cohort study. Am J Manag Care 10:S216-S228

39. Wysowski DK (2010) Oral bisphosphonates and oesophageal cancer. BMJ 341:c4506

40. Perkins AC, Blackshaw DE, Hay PD et al (2008) Esophageal transit and in vivo disintegration of branded risedronate sodium tablets and two generic formulations of alendronic acid tablets: a single-center, single-blind, six-period crossover study in healthy female subjects. Clin Ther 30:834-844

41. Gold DT, Silverman S (2006) Review of adherence to medicationsfor the treatment of osteoporosis. Curr Osteoporos Rep 4:21-27

42. Rossini M, Bianchi G, Di MO et al (2006) Determinants of adherence to osteoporosis treatment in clinical practice. Osteoporos Int 17:914-921

43. Strampel W, Emkey R, Civitelli R (2007) Safety considerations with bisphosphonates for the treatment of osteoporosis. Drug Saf 30:755-763
44. Imaz I, Zegarra P, Gonzalez-Enriquez J, Rubio B, Alcazar R, Amate JM (2010) Poor bisphosphonate adherence for treatment of osteoporosis increases fracture risk: systematic review and metaanalysis. Osteoporos Int 21:1943-1951

45. Sheehy O, Kindundu CM, Barbeau M, LeLorier J (2009) Differences in persistence among different weekly oral bisphosphonate medications. Osteoporos Int 20:1369-1376

46. Weycker D, Macarios D, Edelsberg J, Oster G (2006) Compliance with drug therapy for postmenopausal osteoporosis. Osteoporos Int 17:1645-1652

47. Halkin H, Dushenat M, Silverman B (2007) Brand versus generic alendronate: gastrointestinal effects measured by resource utilization. Ann Pharmacother 41:29-34

48. Sheehy O, Kindundu C, Barbeau M, LeLorier J (2009) Adherence to weekly oral bisphosphonate therapy: cost of wasted drugs and fractures. Osteoporos Int 20:1583-1594

49. Grima DT, Papaioannou A, Thomson MF, Pasquale MK, Adachi JD (2008) Greater first year effectiveness drives favourable costeffectiveness of brand risedronate versus generic or brand alendronate: modelled Canadian analysis. Osteoporos Int 19:687-697

50. Ringe JD, Möller G (2009) Differences in persistence, safety and efficacy of generic and original branded once weekly bisphosphonates in patients with postmenopausal osteoporosis: 1-year results of a retrospective patient chart review analysis. Rheumatol Int 30:213-221

51. Ensrud KE, Barrett-Connor EL, Schwartz A et al (2004) Randomized trial of effect of alendronate continuation versus discontinuation in women with low BMD: results from the Fracture Intervention Trial long-term extension. J Bone Miner Res 19:1259-1269

52. Neele SJ, Evertz R, Valk-De Roo G, Roos JC, Netelenbos JC (2002) Effect of 1 year of discontinuation of raloxifene or estrogen therapy on bone mineral density after 5 years of treatment in healthy postmenopausal women. Bone 30:599603

53. Yood RA, Emani S, Reed JI, Lewis BE, Charpentier M, Lydick E (2003) Compliance with pharmacologic therapy for osteoporosis. Osteoporos Int 14:965-968

54. Caro JJ, Ishak KJ, Huybrechts KF, Raggio G, Naujoks C (2004) The impact of compliance with osteoporosis therapy on fracture rates in actual practice. Osteoporos Int 15:1003-1008

55. Huybrechts KF, Ishak KJ, Caro JJ (2006) Assessment of compliance with osteoporosis treatment and its consequences in a managed care population. Bone 38:922-928

56. Siris ES, Harris ST, Rosen CJ et al (2006) Adherence to bisphosphonate therapy and fracture rates in osteoporotic women: relationship to vertebral and nonvertebral fractures from 2 US claims databases. Mayo Clin Proc 81:1013-1022

57. Olszynski WP, Adachi J, Davison J, Davison KS (2010) Disintegration times of brand and generic bisphosphonates available in Canada. J Bone Miner Res 25:S125

58. Epstein S, Cryer B, Ragi S et al (2003) Disintegration/dissolution profiles of copies of Fosamax (alendronate). Curr Med Res Opin 19:781-789

59. Dansereau RJ, Crail DJ, Perkins AC (2008) In vitro disintegration and dissolution studies of once-weekly copies of alendronate sodium tablets $(70 \mathrm{mg})$ and in vivo implications. Curr Med Res Opin 24:1137-1145

60. Dansereau RJ, Crail DJ, Perkins AC (2009) In vitro disintegration studies of weekly generic alendronate sodium tablets $(70 \mathrm{mg})$ available in the US. Curr Med Res Opin 25:449-452

61. Almeida S, Almeida A, Filipe A et al (2006) In vitro disintegration and dissolution and in vivo bioequivalence of two alendronate once-weekly formulations. Arzneimittelforschung $56: 84-89$ 
62. Lamprecht G (2009) In vitro determination of the release of alendronic acid from alendronate tablets of different brands during deglutition. J Pharm Sci 98:3575-3581

63. Perkins AC, Wilson CG, Frier M, Vincent RM, Blackshaw PE, Dansereau RJ, Juhlin KD, Bekker PJ, Spiller RC (1999) Esophageal transit of risedronate cellulose-coated tablet and gelatin capsule formulations. Int J Pharm 186:169-175

64. Epstein S, Geusens P, Fisher JE et al (2005) Disintegration and esophageal irritation profiles of alendronate formulations: implications for clinical safety and efficacy. J Applied Res 5:253-264

65. Shakweh M, Bravo-Osuna I, Ponchel G (2007) Comparative in vitro study of oesophageal adhesiveness of different commercial formulations containing alendronate. Eur J Pharm Sci 31:262-270
66. Department of Heath and Ageing (2011) Australian public assessment report for alendronic acid. Australian Government, Department of Health and Ageing Therapeutics Goods Administration. Submission PM-01135-3-5, February 2011

67. Hiligsmann M, Rabenda V, Gathon HJ, Ethgen O, Reginster JY (2010) Potential clinical and economic impact of nonadherence with osteoporosis medications. Calcif Tissue Int 286:202-210

68. Hiligsmann $\mathrm{M}$, Gathon $\mathrm{HJ}$, Bruyère $\mathrm{O}$, Ethgen $\mathrm{O}$, Rabenda $\mathrm{V}$, Reginster JY (2010) Cost-effectiveness of osteoporosis screening followed by treatment: the impact of medication adherence. Value Health 13:394-401

69. Strom O, Borgstrom F, Kanis JA, Jonsson B (2009) Incorporating adherence into health economic modelling of osteoporosis. Osteoporos Int 20:23-34 